\title{
SISTEM PENGISIAN PULSA PADA KWH METER PRABAYAR MENGGUNAKAN PONSEL
}

\section{PULSE FILLING SYSTEM ON PREPAID ELECTRICAL ENERGI METER USING MOBILE PHONE}

\author{
Asep Mulyana ${ }^{1}$, Tengku Ahmad Riza², Dadan Nur Ramadan², Muhammad Dzakwan Falih ${ }^{4}$ \\ 1,2,3,4 Universitas Telkom, Jalan Telekomunikasi No 1, Terusan Buahbatu, Bandung \\ 12asepmulyana@tass.telkomuniversity.ac.id, ${ }^{2}$ tengkuriza@tass telkomuniversity.ac.id, \\ 3 dadan.nr@tass.telkomuniversity.ac.id, 4dzakwanfalih@hotmail.com
}

\begin{abstract}
Abstrak
Saat ini terdapat dua cara sistem pembayaran (billing system) daya listrik yang diterapkan PT. PLN, yakni sistem konvensional dan sistem token. Pada sistem token, buzzer digunakan sebagai sistem peringatan dini apabila pulsa akan habis, dan proses pengisisan pulsa harus dilakukan di lokasi dimana KWH meter berada, dimana hal ini kurang bermanfaat apabila pengguna tidak berada di dekat alat tersebut. Dalam penelitian ini dilakukan perancangan KWH Meter dijital untuk sistem token, dengan menggunakan Arduino Uno yang dilengkapi dengan modul komunikasi berbasis SMS, sistem dapat berkomunikasi dengan penggunan melalui SMS, untuk melakukan pengecekan dan pengisian kuota KWH Meter, serta memberikan peringatan dini (reminder) apabila sisa kuota pada KWH Meter hampir habis, sehingga jarak tidak lagi menjadi kendala. Hasil pengujian sistem menunjukkan akurasi alat KWH Meter 99.34\%, rata-rata delay pengisian pulsa kuota KWH Meter (round trip delay): 12,25 detik, delay pengecekan posisi KWH Meter (round trip delay): 14,25 detik, dan delay notifikasi peringatan dini (one way delay): 7,15 detik.
\end{abstract}

Kata kunci: KWH Meter prabayar, KWH Meter pintar, monitoring KWH Meter, peringatan dini sisa kuota KWH Meter.

\begin{abstract}
Currently there are two ways of payment system (billing system) electrical power applied by PT. PLN, ie conventional system and token system. In the token system, buzzer is used as early warning system when the pulse will be exhausted, and for pulse filling process should be done at the location where KWH meter is located, which is less useful if the user is not near the tool. In this research, digital KWH Meter is design for token system, using Arduino Uno which is equipped with SMS communication module, the system can communicate with users via SMS, to check and fill KWH Meter quota, and give warning reminder if the quota on the KWH Meter is running low, so distance is no longer a constraint. The results of the system test show the accuracy of KWH Meter $99.34 \%$, the average delay response of updating of the balance of KWH Meter (round trip delay) is 12,25 seconds, the delay response of balance checking of KWH Meter (round trip delay) is 14,25 seconds, and the delay of the early warning system (one way delay) is 7,15 seconds.
\end{abstract}

Keywords: Prepaid KWH Meter, Smart KWH Meter, early warning of power source billing system.

\section{PENDAHULUAN}

Dalam penelitian ini lebih difokuskan pada penambahan fitur sistem billing pada KWH Meter. Adapun perancangan KWH Meternya sendiri merupakan kelengkapan yang harus dibuat untuk merealisasikan sistem biling tersebut. Oleh karenanya itu dalam dan pengujian tidak mengekplorasi akurasi KWH Meter karena hal ini sudah sangat banyak dilakukan penelitian 
sebelumnya. Karena itu dalam pengujian tidak dilakukan untuk kondisi beban induktif dan kapasitif melainkan hanya untuk kondisi beban resistf. Namun demikian sistem KWH Meter yang dirancang menggunakan komponen berdasarkan penelitian sebelumnya yang telah melalui pengujian akurasi KWH Meter untuk berbagai kondisi beban tsb. Oleh karena itu, sebagai pembanding beberapa penelitian sebelumnya adalah yang terkait dengan sistem biling KWH Meter yaitu[1,2], dengan melakukan pengukuran pemakaian daya untuk tujuan monitoring. Perbedaan pada penelitian yang pertama sistem monitoring berbasis WEB, sedangkan yang kedua berbasis SMS, namun keduanya tidak membahas metoda prabayar maupun sistem peringatan dini.

Penelitian berikutnya[3] dapat merealisasikan pentransferan posisi KWH Meter ke server terpusat, namun terdapat kendala yaitu, tidak merealisasikan sistem pengisian kuota KWH Meter prabayar, dan tidak menggunakan system peringatan dini. Selanjutnya[4] dengan sistem yang ditambahkan pada KWH Meter lebih difokuskan pada sistem informasi tentang besarnya biaya rekening listrik yang harus dibayar yang dikirimkan dari perangkat pada KWH Meter ke ponsel pelanggan, serta membuat tambahan sistem pembayaran listrik melalui perangkat KWH Meter yang dilengkapi mesin magnetic reader dan keypad dengan pembayaran menggunakan kartu debit.

Dari penelitian yang telah dilakukan kekurangannya adalah, pembayaran masih tetap harus dilakukan di dekat KWH Meter, disamping itu tambahan perangkatnya (magnetic reader) menjadi lebih "costly", serta tidak terdapat fitur peringatan dini untuk menghindari terputusnya listrik tibatiba, Berikutnya[5] merupakan alat monitoring besarnya beban (KWH Meter) untuk melakukan pengontrolan (pemutusan/penyambungan atau on/off) melalui ponsel jika pemakaian daya sudah mencapai batas angka yang telah ditentukan.

\section{DASAR TEORI}

\subsection{Daya Listrik}

Daya listrik merupakan energi per-satuan waktu[6]. Daya yang dibangkitkan oleh elemen aktif atau yang diserap/disimpan elemen pasif adalah sama dengan hasil kali tegangan pada elemen tsb dan arus yang mengalir pada elemen tsb[6].

$$
\begin{aligned}
\text { Daya listrik } & =\frac{\text { energi }}{\text { waktu }}=\frac{\text { energi (joule) }}{\text { muatan }(\text { cuolomb })} \times \frac{\text { muatan }(\text { cuolomb) }}{\text { waktu }(\mathrm{sec})} \\
& =\text { Tegangan } x \text { arus }
\end{aligned}
$$

Daya biasa dinotasikan $\mathrm{P}$, tegangan $\mathrm{V}$, dan arus I. Untuk sumber AC jika beban bersifat resistif dimana tegangan dan arus sefasa, maka besarnya daya : $\mathrm{P}=\mathrm{V} \times \mathrm{I}$ (Watt), dimana seluruh daya terserap (disipasi) oleh beban ke dalam bentuk energi lain berupa cahaya, panas, gerak dll.

Namun jika beban mengandung komponen induktif dan atau kapasitif, maka akan terdapat saat-saat (perioda) dimana tegangan dan arus tidak sefasa sehingga akan timbul komponen daya yang tak berguna. Maka dalam analisis dengan sumber AC dikenal adanya tiga jenis daya yaitu: daya nyata (real power), daya semu (apparent power), dan daya reaktif (reactive power).

Daya nyata disebut juga daya aktif (active power) atau daya rata-rata (average power)[7]. Daya rata-rata merupakan daya yang dihasilkan sebagai integral dari fungsi periodik waktu terhadap keseluruhan rentang waktu perioda dibagi oleh periodanya itu sendiri $[7,8]$ dengan bentuk umum:

$$
P=\int_{0}^{T} v(t) \cdot i(t) d t
$$


Persamaan tsb berlaku umum baik untuk sinyal sinusoidal maupun non sinusoidal. Dalam kenyataannya justru yang sering dijumpai adalah beban yang menyebabkan terdistorsinya sinyal sinusoidal sehingga dalam analisis AC dengan pendekatan (asumsi) bentuk sinyal sinusoidal menjadi kurang akurat [7]. dengan demikian untuk memperoleh akurasi yang lebih baik diperlukan analisis tersendiri yang lebih rumit. Karenanya pendekatan bentuk sinusoidal ini menjadi pilihan umum, berikut penjelasan ketiga jenis daya untuk sumber AC berdasarkan pendekatan sinusoidal.

\subsubsection{Daya Nyata}

Daya nyata merupakan daya yang terserap atau terpakai oleh komponen pasif resistif. Daya inilah yang dicatat oleh alat kWH meter yang dibayar oleh pelanggan. Daya nyata yang dinotasikan $\mathrm{P}$ secara matematis merupakan perkalian antara tegangan efektif, arus efektif, dan koefisien faktor dayanya dengan satuan Watt[8].

$$
P=V_{\text {eff }} x I_{\text {eff }} x \operatorname{Cos} \varphi
$$

Dengan Veff atau Vrms $=(1 / \sqrt{ } 2) \mathrm{Vm}$, Irms $=(1 / \sqrt{ } 2) \mathrm{Im}$, dimana Vm dan Im masing-masing merupakan amplituda dari tegangan dan arus, sedangkan $\varphi$ merupakan sudut fasa yakni beda fasa antara tegangan dan arus[7].

\subsubsection{Daya Reaktif}

Daya reaktif merupakan daya yang timbul yang diakibatkan oleh komponen pasif diluar komponen resistif yang merupakan rugi-rugi daya atau daya yang tidak diinginkan. Untuk efisiensi daya ini sejauh mungkin diminimalisir mungkin antara lain dengan kompensasi atau perbaikan perbaikan faktor daya, walaupun tidak akan hilang sama sekali. Daya reaktif dinotasikan Q dengan satuan VAR (Volt Ampere Reactive). Secara matematis daya reaktif merupakan perkalian tegangan efektif, arus efektif, dan nilai $\operatorname{Sin} \varphi$ [8]

$$
Q=V_{\text {eff }} x I_{\text {eff }} x \operatorname{Sin} \varphi
$$

\subsubsection{Daya Semu}

Merupakan daya yang sebenarnya dicatu (supplied) oleh pembangkit (PLN). Daya semu dinotasikan S merupakan resultan dari daya aktif dan daya reaktif dengan satuan VA (Volt Ampere). Secara matematis ditulis: [8]

$$
S=V_{\text {eff }} x I_{\text {eff }}
$$

\subsection{Segitiga Daya dan Faktor Daya[4]}

Ketiga komponen daya tsb ( $\mathrm{P}, \mathrm{Q}$, dan $\mathrm{S})$ secara fasor dapat digambarkan seperti pada Gambar 1 berikut: 


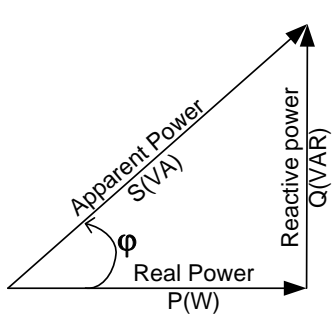

(a)

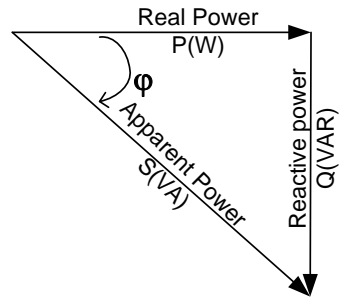

(b)

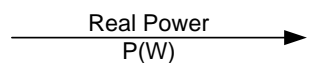

(c)

Gambar 1. Segitiga Daya (a) beban induktif, (b) beban capasitif, (c) beban resistif [8]

Perbandingan $\mathrm{P} / \mathrm{S}$ atau $\operatorname{Cos} \varphi$ disebut faktor daya atau power factor disingkat pf. Untuk beban yang bersifat induktif, tegangan akan mendahului arus (leading) sehingga beda fasa akan bernilai positif seperi pada Gambar 1(a). Untuk beban yang bersifat kapasitif, tegangan akan terbelakang dari arus sehingga beda fasa akan bernilai negatif seperi pada Gambar 1(b). Sedangkan jika beban bersifat resistif, tegangan dan arus sefasa atau $\varphi=0$ seperti Gambar 1(c) sehingga nilai $\operatorname{Cos} \varphi=1$ dan nilai $\mathrm{P}=\mathrm{S}$.

\subsection{Pengukuran Daya dan Faktor Daya}

Pada dasarnya, sebuah Power Meter dirancang untuk mengukur energi listrik. Jika sampelsampel tegangan sesaat Vi dan arus sesaat Ii dapat diukur secara periodik (sampling) dengan perioda sampling (sampling rate) atau frekuensi sampling minimal dua kali frekuensi maksimal dari tegangan dan arus tersebut (Teori Nyquist), maka akan didapat harga rata-rata tegangan (Vrms) dan harga rata-rata arus (Irms) dimana hasil perkalian keduanya merupakan daya semu atau apparent power $\mathrm{S}$.

Untuk memperoleh daya aktif $\mathrm{P}(\mathrm{W})$, harus diketahui faktor daya $(\operatorname{Cos} \varphi)$ dimana $\varphi$ merupakan beda fasa antara tegangan dan arus. Untuk memperoleh beda fasa ini secara garis besar terdapat dua metoda yakni secara pengukuran dan metoda analitik (pendektan matematis). Contoh yang menggunakan pendekatan matematis adalah[9]. Sedangkan yang menggunakan metoda pengukuran yang disebu dengan pengukuran Zero Crossing dengan menggunakan komponen utama komparator dan exo adalah[10,11] dengan kelebihan dan kekurangan masing-masing. Dalam penelitian ini seperti dikemukakan di awal, tidak melakukan analisis erhadap akurasi dayanya itu sendiri melainkan lebih difokuskan pada fitur komunikasinya.

\subsection{Sensor tegangan dan arus}

Tegangan dan arus yang akan diukur merupakan tegangan jala-jala dan arus beban yang cukup besar sehingga untuk memungkinkan dapat diukur oleh mikrokontroler perlu sensor tegangan dan sensor arus sebagai pengkondisi sinyal antara jala-jala dengan mikrokontroler. Karakteristik keluaran sensor sebaiknya selinier mungkin (berbanding lurus) dengan besaran tegangan/arus masukan snsor agar diperoleh hasil ukur seakurat mungkin. Di pasaran terdapat banyak jenis, merek, dan tipe sensor tegangan dan arus. Dalam penelitian ini menggunakan sensor yang telah terbukti akurasinya cukup baik berdasarkan penelitian sebelumnya[11].

\subsection{Mikrokontroler}

Mikrokontroler merupakan salah satu komponen utama atau bagian dasar dari suatu sistem komputer. Suatu mikrokontroler pada dasarnya dibangun dari elemen-elemen dasar yang sama[8]. Yang berbeda adalah fitur dan ukuran/kapasitasnya Salah satu tipe mikrokontroler yang banyak 
digunakan karena memiliki fitur yang banyakdibutuhkan seperti untuk implementasi robotika adalah ATmega 32.

\section{PERANCANGAN SISTEM}

\subsection{Model sistem}

Dalam implementasi yang sesungguhnya jika model ini telah dioperasikan akan nampak seperti pada Gambar 3, namun dalam percobaan ini sebagai server biling yang ada di operator seluler tidak dibuat prototype-nya, melainkan hanya memanfaatkan respon sistem pengisian pulsa untuk SIM card perangkat KWH Meter.

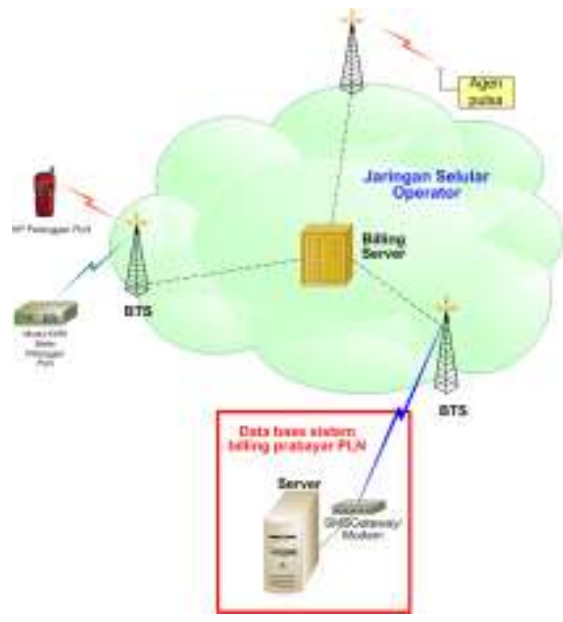

Gambar 2. Model system

\subsection{Rancangan perangkat hardware.}

Secara blok diagram, rancangan perangkat hadware di sisi pelanggan seperti diperlihatkan pada Gambar 4.

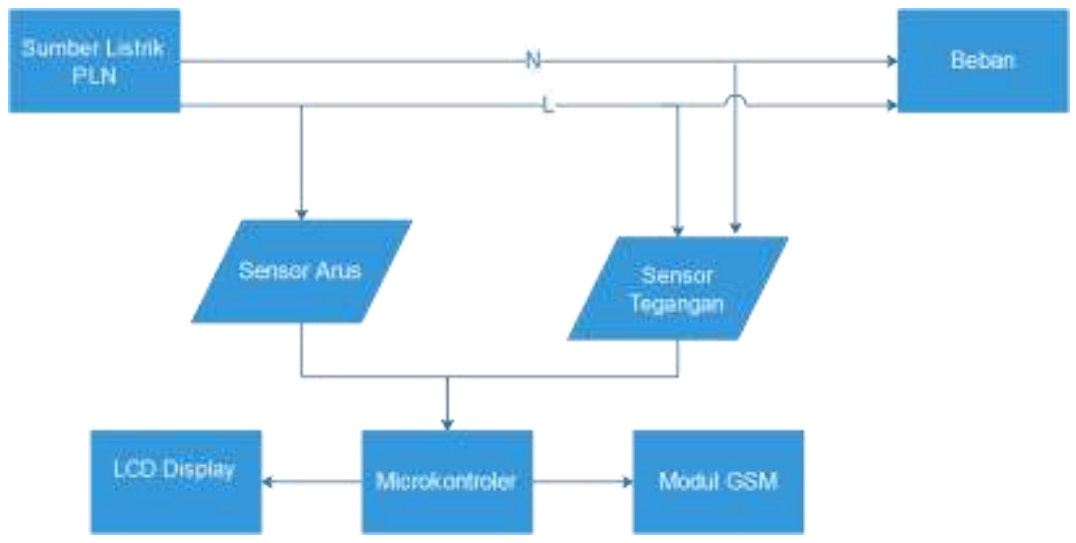

Gambar 3. Blok diagram perangkat hardware (pada pelanggan)

Dalam rancangan ini sensor tegangan yang digunakan adalah ZMPT101B, sensor arus menggunakan YHDC SCT-013-000 CT 100A, dan sebagai pemroses data untuk pembacaan hasil ukur, penampilan pada LCD serta proses komunikasi dengan jaringan seluler untuk pengisian pulsa (kuota KWH Meter), untuk pengecekan posisi KWH Meter serta pengiriman notifikasi peringatan dini adalah menggunakan Arduino Uno yang dilengkapi SMS Gateway SIM900. Gambar 5 berikut adalah foto eksperimen. 


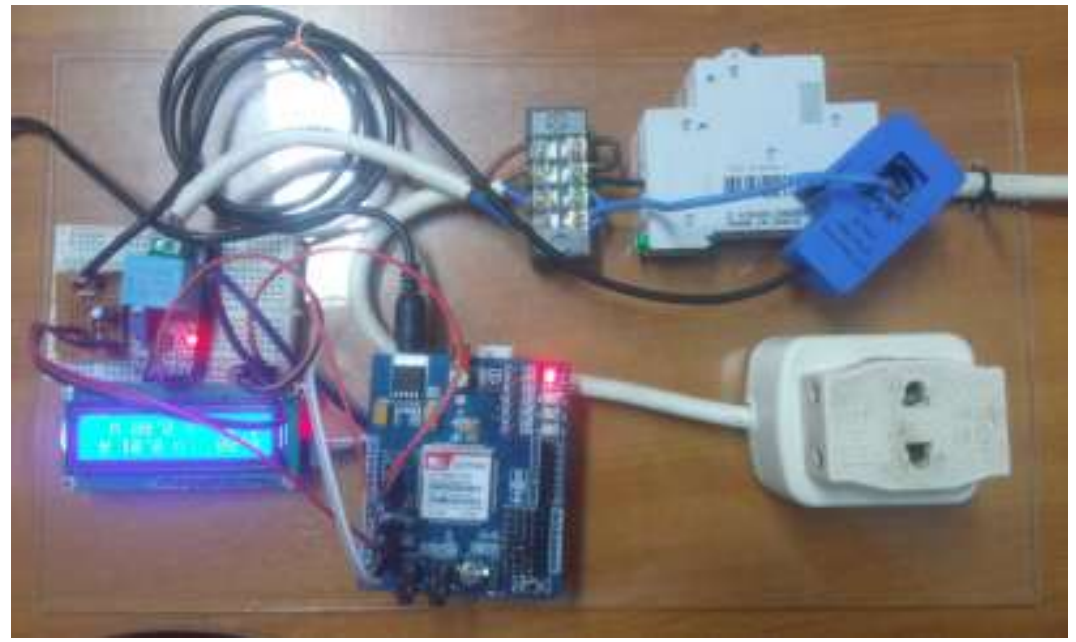

Gambar 4. Foto rangkaian eksperimental

\subsection{Perancangan software pada mikrokontroler}

Peringantan dini yang dibuat, bertujuan untuk menghindari pemutusan listrik secara tiba-tiba dikarenakan pulsa listrik yang habis, meskipun terdapat notifikasi pada system yang sudah ada, yaitu berupa buzzer, namun system tersebut hanya dapat memberikan notifikasi apabila penggunan berada didekat KWH meter tersebut. Dengan ditambahkannya peringatan dini berupa SMS, maka pengguna dapat menerima SMS peringatan akan sisa pulsa meskipun tidak berada pada posisi di dekat KWH meter. Perancangan software pada mikrokontroler di sisi pelanggan diperlihatkan pada Gambar 5.

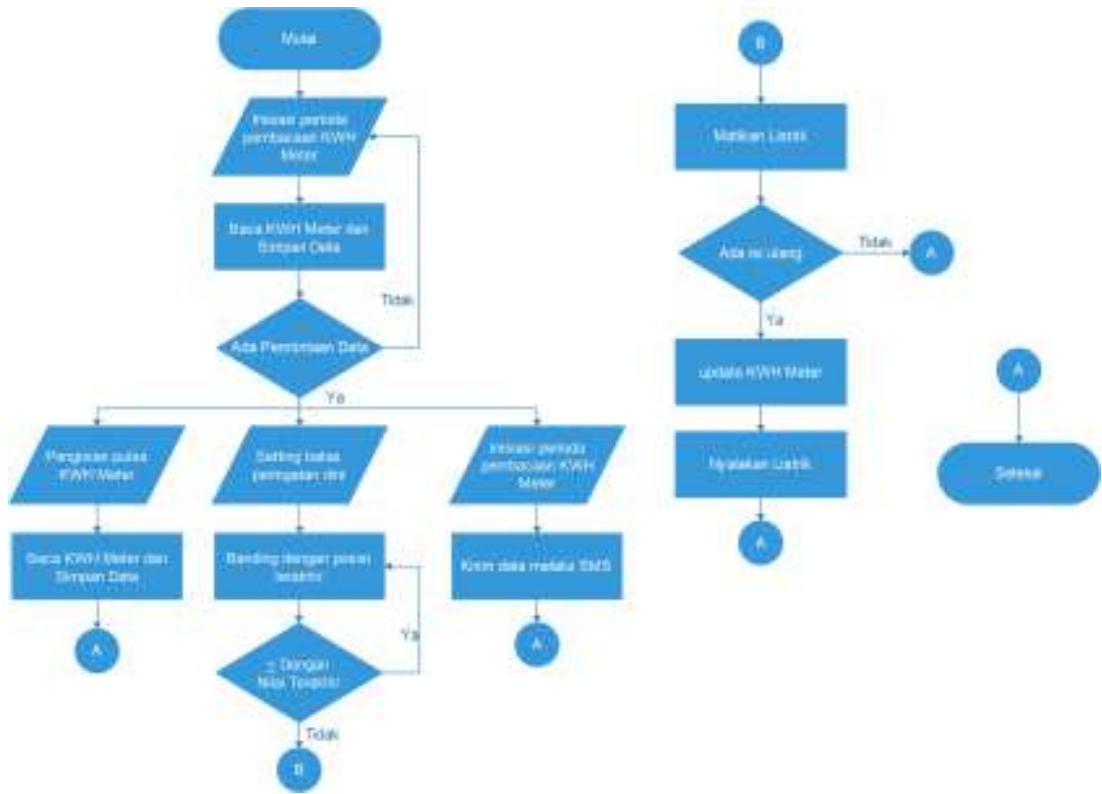

Gambar 5. Diagram Alir Perancangan Software pada Mikrokontroler

Pada Gambar 6 menampilan LCD pada KWH meter pada sistem yang dibuat, menunjukan pembacaan tegangan, arus dan daya yang dipergunakan pada saat pengukuran dan diberi beban, pada Gambar 7 LCD memberikan pemberitahuan bahwa sistem telah mengirimkan SMS notifikasi ke pengguna, karena sisa pulsa hamper habis, pada saat pengujian di setting ababila besaran pulsa dibawah 5.00, maka sistem akan mengirimkan notifikasi berupa SMS. 


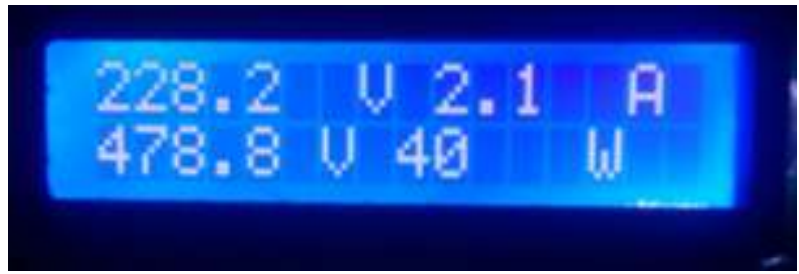

Gambar 6. Tampilan LCD ketika pengukuran

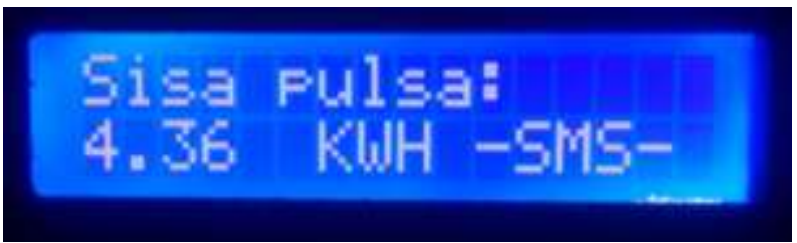

Gambar 7. Tampilan LCD ketika sistem mengirimkan notifikasi

Untuk mempermudah proses monitoring apabila pengguna tidak berada di dekat KHW meter, maka sistem dibuat untuk dapat berkomunikasi dengan penggunan melalui SMS, untuk melakukan cek sisa pulsa, memberi peringatan bahwa pulsa akan habis dan menerima pengisian pulsa, dengan code sebagai berikut;

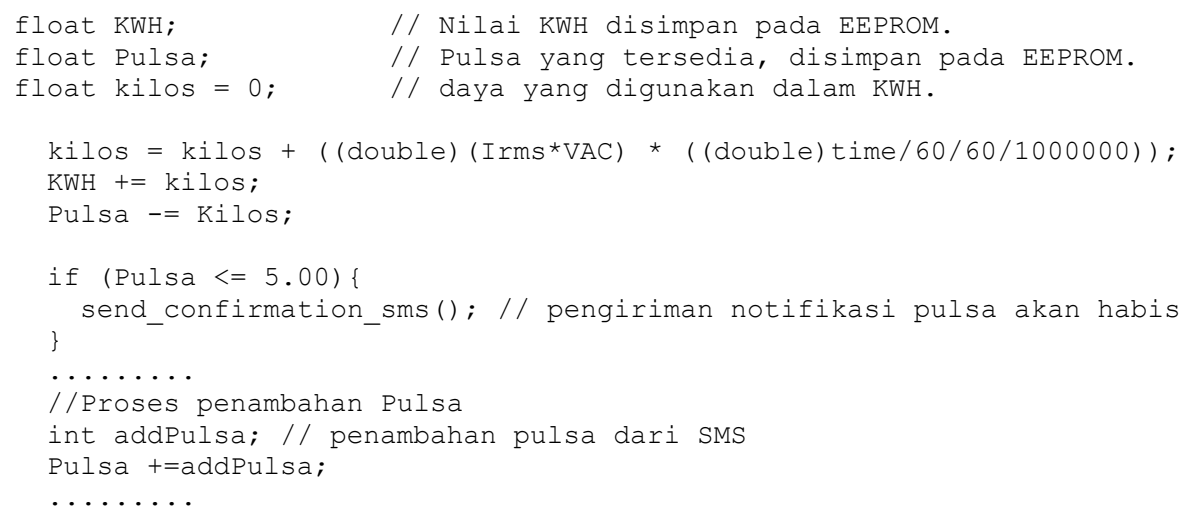

\subsection{Hasil pengujian}

\subsubsection{Hasil pengujian tegangan}

Dalam pengujian tegangan, dilakukan 4 skenario setting tegangan $(158 \mathrm{~V}, 180 \mathrm{~V}, 200 \mathrm{~V}$ dan $225 \mathrm{~V}$ ) dengan menggunakan variable resistor (dimmer). Dari masing-masing skenario tsb kemudian diambil sampel pengukuran sebanyak 40 sampel. Rata-rata hasil pengukuran seperti pada Tabel-1

Tabel 1 Rata-rata hasil pengukuran tegangan

\begin{tabular}{|c|c|c|c|}
\hline No & $\begin{array}{c}\text { Pengukuran } \\
\text { Tegangan } \\
\text { Menggunakan Alat } \\
\text { Ukur (Volt) }\end{array}$ & $\begin{array}{c}\text { Pengukuran } \\
\text { Tegangan } \\
\text { Menggunakan } \\
\text { Sensor (Volt) }\end{array}$ & Error (\%) \\
\hline 1 & 158 & 160.0005 & 1.266 \\
\hline 2 & 180 & 179.455 & 0.303 \\
\hline 3 & 200 & 198.2985 & 0.851 \\
\hline
\end{tabular}


Jurnal Elektro Telekomunikasi Terapan Desember 2017

\begin{tabular}{|l|l|l|l|}
\hline 4 & 225 & 225.7665 & 0.103 \\
\hline
\end{tabular}

Dari hasil pengujian tegangan tersebut dengan rata-rata error perangkat $0.63 \%$, maka berarti akurasi sensor tegangan $=100 \%-0.63 \%=99.37 \%$

\subsubsection{Hasil pengujian arus}

Dalam pengukuran arus, dilakukan dengan memberi beban beban 0, 50, 125 dan 400 Watt dimana arus terukur oleh alat ukur pembanding masing-masing 0.02A, 0.37A, 1.804A, dan 2.18A. Kemudian dilakukan pengukuran secara sampling dengan jumlah sampel 40 sampel untuk tiap nilai beban tsb. Diperoleh hasil rata-rata sperti pada Tabel-2

Tabel 2 Rata-rata hasil pengukuran arus

\begin{tabular}{|c|c|c|c|c|}
\hline No & Beban (Watt) & $\begin{array}{c}\text { Pengukuran Arus } \\
\text { Menggunakan Alat } \\
\text { Ukur (Ampere) }\end{array}$ & $\begin{array}{c}\text { Pengukuran Arus } \\
\text { Menggunakan } \\
\text { Sensor (Ampere) }\end{array}$ & Error (\%) \\
\hline 1 & 0 & 0.02 & 0.07625 & 2.2812 \\
\hline 2 & 50 & 0.37 & 0.36 & 0.0270 \\
\hline 3 & 400 & 1.8 & 1.804 & 0.0022 \\
\hline 4 & 500 & 2.16 & 2.18 & 0.0093 \\
\hline
\end{tabular}

Dari hasil pengujian arus tersebut dapat diperoleh kesimpulan rata-rata error perangkat untuk mengukur arus adalah sebesar $0.71 \%$. Hal ini berarti akurasi sensor arus $=100 \%-0.71 \%=\mathbf{9 9 . 2 9 \%}$.

Selanjutnya untuk perhitungan daya, karena bebannya berupa lampu pijar yang berarti beban resistif, beda fasa nol, maka besarnya daya aktif (daya nyata) merupakan hasil perkalian tegangan dan arus di atas $\left(\mathrm{V}_{\text {eff }}\right.$ dan $\left.\mathrm{I}_{\text {eff }}\right)$ dalam Watt. Dengan akurasi berdasarkan atas akurasi rata-rata tegangan dan arus, yaitu $=(99.37 \%-99.29 \%) / 2=\mathbf{9 9 . 3 4 \%}$

\subsubsection{Hasil pengujian delay SMS}

Untuk pengujian fitur-fitur delay pengisian pulsa kuota KWH Meter, pengecekan posisi KWH Meter, dan notifikasi peringatan dini, dilakukan simulasi berupa komunikasi interaktif antara SIM card pada KWH Meter (yang dikontrol oleh mikrokontroler Arduino) dengan sebuah smart phone, dimana dalam smart phone tsb diinstalasi Wireshark for android. Percobaan dilakukan masing-masing 40 kali dan dipeoleh hasil rata-rata delay pengisian pulsa kuota KWH Meter (round trip delay): 12.25, delay penecekan posisi KWH Meter (round trip delay): detik, 14.25 detik, dan delay notifikasi peringatan dini (one way delay): 7.15 detik. 

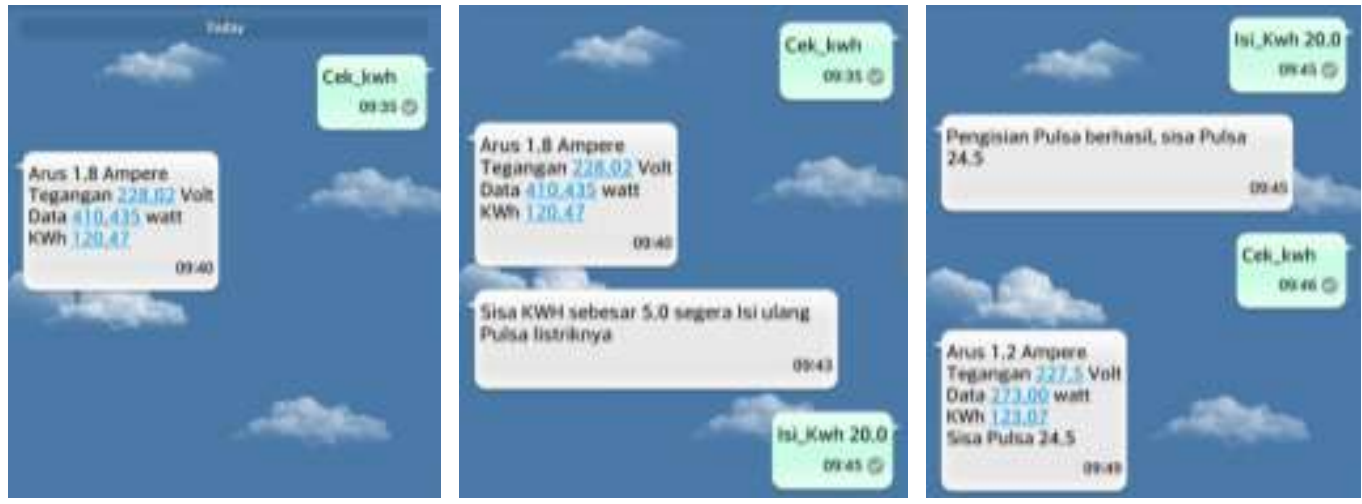

Gambar 8. Pengujian SMS pada Smartphone

\section{KESIMPULAN}

Dari penelitian yang telah dilakukan dapat disimpulkan sebagai berikut:

1. Dari hasil pengujian secara fungsional perangkat hasil rancangan dapat melakukan fungsinya sebagaimana yang direncanakan

2. Tingkat akurasi alat berdasarkan hasil pengukuran arus dan tegangan rata-rata adalah $99.34 \%$

3. Sementara hasil pengujian pengiriman SMS sebagai simulasi sistem billing memberikan hasil: rata-rata delay pengisian pulsa kuota KWH Meter (round trip delay): 12,25 detik, delay pengecekan posisi KWH Meter (round trip delay): 14,25 detik, dan delay notifikasi peringatan dini (one way delay): 7,15 detik

\section{DAFTAR PUSTAKA}

[1] Dadan Nur Ramadan, Agus Ganda Permana, Galuh Mardiansyah, Dyah Puspaningrum, Rancang Bangun dan Implementasi Alat Ukur dan Sistem Informasi Pada Listrik Satu Fasa, JETT Volume 2, Nomor 2, Tahun 2015.

[2] Yulizar, Ira Devi Sara, Mahdi Syukri, Prototipe Pengukuran Pemakaian Energi Listrik Pada Kamar Kos Dalam Satu Hunian Berbasis Arduino Uno R3 dan GSM Shield SIM900, KITEKTRO: Jurnal Online Teknik Elektro, e-ISSN: 2252-7036 Vol.1 No.3 2016: 47-56.

[3] Md. Abul Bashar, Maruf Ahmad, Sobuj Kumar Ray, Asif Ahmed, Economical Way of GPRS Based Fully Automated Energy Metering System, International University Bangladesh, Global Journal of Computer Science and Technology Network, Web \& Security Volume 13 Issue 3 Version 1.0 Year 2013.

[4] S. Chhettri, A.K. Nath and M.A. Ahmed, GSM Based Automated Meter Reading With Bill Payment Facility, International Journal of Emerging Trends in Electrical and Electronics (IJETEE - ISSN: 2320-9569) Vol. 4, Issue. 1, June-2013.

[5] Afrizal Tanjung, Rozeff Pramana, ST.,MT, Sapta Nugraha, S, Prototype Sistem Monitoring Daya Pada KWH Meter 1 Phase dan Sistem Kontrol on/off via SMS Modue, Teknik Elektro UMRAH - 2017.

[6] Giorgio Rizzoni, Fundamentals of Electrical Engineering, first edition, McGraw-Hill, New York, 2009.

[7] Roger C.Dugan, Mark F. McGranaghan, Surya Santoso, H.Wayne Beaty, Electrical Power Systems Quality, Second Edition, McGraw-Hill, 2004.

[8] Mohamad Ramdhani, Rangkaian Listrik, Erlangga, Jakarta, 2009. 
[9] Ageng Pidaksa, Wattmeter Digital AC Berbasis Mikrokontroler ATMEGA8, Teknik Elektronika F.T. UNY.

[10] Husnawati, Rossi Passarella, Sutarno, Rendyansyah, Perancangan dan Simulasi Energi Meter Digital Satu Phasa Menggunakan Sensor Arus ACS712, JNTETI, Vol. 2, No. 4, November 2013. 307.

[11] Mohamed Maher Ibrahim, Smart Energy Monitor, Graduated Engineer for Faculty Engineering, Electrical Power and Machine Engineering Department. 